\title{
Jornalismo, gêneros e diversidade cultural nas revistas brasileiras
}

\author{
Ana Regina Rêgo* \\ Ranielle Leal Moura**
}

\section{Resumo}

Este artigo apresenta os resultados de uma pesquisa realizada em três publicações jornalísticas brasileiras de caráter cultural, a saber: Cult, Bravo e Brasileiros, que foram analisadas com o objetivo de identificar a visibilidade das manifestações culturais em suas páginas, por meio do mapeamento das matérias veiculadas. Em outro prisma, o intuito foi mapear os gêneros jornalísticos mais trabalhados na veiculação das matérias referentes à cultura, com vistas a identificar o grau de importância dado ao temas culturais retratados nas publicações, assim como, verificar as tendências no texto do Jornalismo Cultural. A metodologia utilizada no primeiro caso foi o diagnóstico simples e no segundo caso foi análise de conteúdo por emparelhamento. Ao final conclui-se que embora o Jornalismo Cultural brasileiro esteja se abrindo para divulgar a diversidade do país, ainda permanece uma predominância destacável dos eventos do sudeste entre os temas pautados pelas publicações citadas.

Palavras chave: Manifestações Artísticas. Cultura da Mídia. Cultura de Consumo. Jornalismo Cultural.

\footnotetext{
* Professora do Programa de Pós-Graduação em Comunicação, Centro de Ciências da Educação, Universidade Federal do Piauí, Teresina-PI, Brasil. Doutora em Comunicação pela Universidade Metodista de São Paulo com estágio de doutorado na UAB- Universidade Autônoma de Barcelona. Ex-Gerente Regional de Marketing e Comunicação da CAIXA Econômica Federal. Ex-Consultora Ad hoc da Coordenadoria de Comunicação do Governo do Piauí. Colunista do Jornal O Dia. Franqueada Social do Projeto Casa da Criança. Coordenadora do NUJOC- Núcleo de Pesquisa em Jornalismo e Comunicação. Coordenadora do Projeto Memória do Jornalismo Piauiense. Autora dos livros: Imprensa Piauiense-atuação Política no século XIX, e, Jornalismo Cultura e Poder. Contatos: ana.rani@uol.com.br

** Diretora Técnica do Instituto de Comunicação e Cultura. Coordenadora de Comunicação do Ministério Público do Piauí, Teresina-PI, Brasil. MBA em Marketing pela Fundação Getulio Vargas- RJ. Mestre em Comunicação pela UMESP. Universidade Metodista de São Paulo. Autora do livro: O Olhar e a Palavra - o FotoJornalismo de José Medeiros na Revista O Cruzeiro. Contatos: rani. leal@uol.com.br
} 
Journalism, genders journalistic and cultural diversity in Brazilians magazines

\section{Abstract}

This article presents the results of a research performed in three Brazilian publications journalistic cultural character, namely: Cult, Bravo and Brazilians, were analyzed with the objective to identify the visibility of cultural events in its pages, through the mapping of materials circulated. In another way, the goal was to map the genders journalistic more worked role in disseminating with matters relating to culture, with a view to identify the degree of importance given to cultural themes depicted in publications, as well as, to verify the trends in the text of journalism cultural. The methodology used in the first case was the simple diagnosis and in the second case was contents analysis by pairing. At the end it was concluded that although brazilian cultural journalism is open to promote the diversity of the country, however still there predominance of events of Southeast between news of the publications cited.

Keywords: Culture. Cultural expression. Media cultura. Culture of consumption. Cultural journalism.

\section{Periodismo, géneros periodísticos y diversidad cultural en las publicaciones brasileñas}

\section{Resumen}

Esto artículo presenta los resultados de un estudio de tres publicaciones culturales de Brasil, a saber: Cult, Bravo y Los Brasileños, que fueron analizados con el fin de identificar la visibilidad de los eventos culturales en sus paginas, a través de la cartografía de los artículos publicados. En otra perspectiva, el objetivo era trazar un mapa de los géneros periodísticos, con el fin de identificar el grado de importancia que se da a los temas culturales representados en las publicaciones, así como identificar las tendencias del periodismo cultural. La metodología utilizada en el primer caso fue el diagnóstico y el segundo fue el análisis de contenido por sincronización. Al final se concluyó que si bien que hoy el periodismo es mucho más abierto para promover la diversidad del país, aún sigue destacando mucho más los eventos del sudeste de Brasil.

Palabras clave: Cultura. Expresiones artísticas. Cultura de la media. Cultura del consumo. Periodismo cultural.

\section{Introdução}

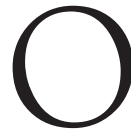

Jornalismo desenvolveu nos dois últimos séculos, um intrínseco relacionamento com a cultura, esta entendida aqui, como a produzida pelas diversas formas de mani- 
festações artísticas e estéticas em todo o mundo. No processo histórico evolutivo vamos observar que em diversos momentos as atividades artísticas, sobretudo, a literária e o Jornalismo têm se encontrado de forma quase híbrida.

Nessa trajetória, o Jornalismo e a literatura estiveram bem próximos até as primeiras décadas do século 20 e o primeiro, muito mais do que oferecer espaço para que a última pudesse ter visibilidade, constituía-se em um campo fértil para o debate e as críticas em torno da produção que acontecia nas diversas escolas literárias ao longo da história. Esse relacionamento influenciou escritores e moldou estilos. Contudo, nem sempre produziu discursos democráticos considerando que as manifestações que obtinham espaço de visibilidade eram, em um primeiro momento, oriundas da chamada cultura erudita e tinham como objetivo proporcionar distinção social, na concepção de Bourdieu (2008, p.34), tanto aos artistas que produziam, como ao público que consumia. $\mathrm{O}$ processo atual conserva a lógica da distinguibilidade, no entanto, as manifestações que atraem os olhares da mídia, nascem da interação entre as chamadas culturas eruditas, popular e de massa, em um movimento híbrido.

Neste contexto e de acordo com Faro (2006, p.5) o Jornalismo Cultural é na verdade um "[...] território de práticas jornalísticas que tanto reiteram os signos, valores e procedimentos da cultura de massa quanto discursos que revelam tensões contra-hegemônicas características de conjunturas históricas específicas". Este autor é otimista ao afirmar que o Jornalismo Cultural não se encontra completamente preso às práticas mercadológicas e do marketing, já que o campo cultural não se submete completamente a estas e possui amplo poder de se recriar e reinventar. Na contramão, Azancot acredita que infelizmente nas editorias de cultura ainda reina a lucratividade nua e crua (AZANCOT, 2010, s/p).

Assim, o Jornalismo Cultural aqui tratado se refere à prática de produção jornalística opinativa, informativa ou analítica dos elementos e acontecimentos que se apresentam no campo cultural.

O nosso olhar na presente investigação volta-se, portanto, para três publicações jornalísticas que tem como foco as manifestações e a produção cultural. São elas: Bravo, Cult e 
Brasileiros, em seus exemplares de abril, maio, junho e julho de 2010, tomados como amostra, a partir da aplicação do método de definição de amostragem aleatória simples e por sorteio, tendo como universo todos os exemplares do ano de 2010. No que concerne à metodologia realizamos inicialmente um diagnóstico quantitativo que visou detectar a incidência dos temas e do lugar de origem dos mesmos. A seguir adotou-se o método de análise de conteúdo por emparelhamento. Por outro lado, adotamos como metodologia complementar o método quantitativo de mensuração do espaço destinado ao tema em pauta, nas referidas revistas, através da unidade de informação de Morin (1974). O objetivo foi, no primeiro caso, identificar a visibilidade das manifestações culturais, verificando a acessibilidade que possuem às revistas mencionadas, através do mapeamento das matérias veiculadas. Neste momento, buscou-se identificar quais as atividades culturais que possuem maior visibilidade? De onde são oriundas? Nesse primeiro momento da análise definimos como categorias analíticas a identificação do Visível e do Invísivel focando, sobretudo, no visível ou em Quem aparece e no Locus de Quem aparece. Em seguida, o intuito foi mapear os gêneros jornalísticos mais trabalhados na veiculação das matérias referentes à cultura, com vistas a identificar o grau de importância dado ao temas culturais retratados nas publicações citadas e, principalmente, as tendências do Jornalismo que aborda a cultura e suas manifestações. No segundo momento analítico definimos como categoria de análise Como Quem aparece, aparece, na qual os gêneros são os protagonistas do processo. Este texto divide-se em três partes, na primeira delas contextualizamos Cultura da Mídia e de Consumo, no segundo tratamos do Jornalismo Cultural, para finalmente realizarmos o processo analítico.

\section{Cultura da Mídia e Cultura de Consumo}

Partimos do pressuposto de que os textos da cultura na mídia não simples veículos de uma ideologia dominante nem entretenimento puro e inocente. Ao contrário são produções complexas que incorporam discursos sociais e políticos cuja análise e inter- 
pretação exigem métodos de leitura e crítica capazes de articular sua inserção na economia política, nas relações sociais e no meio político em que são criados, veiculados e concebidos (KELLNER, 2001, p.13).

O contexto em que Kellner realiza a afirmação acima é o de investigação dos processos da cultura da mídia norte-americana sob o prisma ideológico, momento em que este autor volta-se para as formas mais contundentes de manifestações culturais midiáticas; no entanto, guardadas as devidas proporções vamos nos apropriar de alguns de seus pensamentos para contextualizar o nosso universo de investigação.

De fato, cultura e mídia se hibridizaram ao longo do século 20 e os reflexos desse relacionamento "intra-uterino" apresentam-se nos dias atuais de forma tão intrínseca que, em muitos aspectos e em alguns ângulos, é impossível separá-las. Para a grande maioria dos jovens com idade inferior a 30 anos é extremamente difícil reconhecer alguma manifestação cultural que não esteja na mídia, a não ser que este participe de uma comunidade tradicional.

Em meio ao processo de fusão em que se lançaram cultura e mídia, a primeira em busca da visibilidade e do reconhecimento, a segunda visando audiência e lucratividade; um fator foi primordial para que os dois campos se alinhassem, a saber: os avanços tecnológicos na área da Comunicação que culminaram com a cada vez mais consistente convergência midiática. Nos dias atuais, "[...] as pessoas passam um tempo enorme ouvindo rádio, assistindo à televisão, freqüentando cinemas, convivendo com música, fazendo compras, lendo revistas e jornais" (KELLNER, 2001, p.11) e, principalmente, conectados à internet através de computadores pessoais, celulares e outros aparelhos que surgem a cada hora. Todos esses suportes emitem informações, mensagens e discursos, são, portanto, influentes diretos na vida das pessoas, e, assim como, afirma Kellner,

[...] trata-se de uma cultura que passou a dominar a vida cotidiana, servindo de pano de fundo onipresente e muitas vezes de sedutor primeiro plano para o qual convergem nossa atenção e nossas atividades, algo que, segundo alguns, está minando a potencialidade e a criatividade humana ( KELLNER, 2001, p.11).

Intercom - RBCC 
Ainda de acordo com este autor, a cultura da mídia termina por influenciar as pessoas em seu modo de pensar, comportar e se relacionar. Sendo determinante na maneira como as pessoas se vêem e como visualizam os outros, ou seja, na construção da imagem e até mesmo da identidade pessoal (KELLNER, 2001, p.10). Isto acontece em decorrência de que a cultura em si, considerados os seus aspectos antropológicos, simbólicos, estéticos e artísticos é algo inerente à vida em sociedade, portanto, praticado e construído a partir do envolvimento coletivo, que molda consensos e permite a reflexividade no imaginário simbólico público, criando traços que se unem em uma identidade, em oposição ao conjunto das práticas culturais, no lócus que reúne a diversidade e o multiculturalismo.

Deste modo, a projeção cultural nos meios de Comunicação potencializa os efeitos da cultura, a ponto de que na sociedade contemporânea "[...] dominada pela mídia, os meios dominantes de informação e entretenimento são uma fonte profunda e muitas vezes não percebida de pedagogia cultural" (KELLNER, 2001, p.10), o que influi na vida humana individual e coletiva como citado no parágrafo anterior. Entretanto, o próprio Kellner reconhece que ao mesmo tempo em que a cultura da mídia emite discursos que veiculam valores de uma cultura dominante ou de consumo, esta também fornece meios para que os indivíduos e a sociedade possam resistir, acatar, modificar ou mesmo se posicionar de forma contrária à sociedade midiática e consumista.

É bem verdade que atualmente, esse processo de construção de discursos culturais e midiáticos diverge do ambiente analisado por Kellner, já que não acontece mais de modo uniforme, nem completamente direcionado, uma vez que as mídias mais utilizadas hoje pelos jovens são reticulares e permitem a interatividade, o que facilita releituras, recriações, reinvenções e hibridações entre as manifestações que se visibilizam pela mídia. Entretanto, esta é somente uma face, já que a própria cultura da mídia se reinventa a cada dia e interage mais e mais com as práticas mercadológicas, através da onipresença de produtos culturais que se alastram entre os produtos de consumo, sejam eles alimentícios, do vestiário etc.

Assim, é também verdade e como afirma Kellner que "[...] a cultura da mídia e a de consumo atuam de mãos dadas no sentido 
JORNALISMO, GÊNEROS E DIVERSIDADE CULTURAL NAS REVISTAS BRASILEIRAS

de gerar pensamentos e comportamentos ajustados aos valores, às instituições, às crenças e às práticas vigentes (KELLNER, 2001, p.11)".

É neste contexto que passamos a perceber o nascimento e a importância dos mediadores e formadores de opinião; uma nova categoria de influentes que orientam e mediam o consumo de todas as naturezas. Dentre eles, vemos com destaque os papéis do publicitário e do jornalista, mas não podemos desconsiderar o intelectual, o político, o artista e os que representavam a fé.

Por outro lado, Cultura da mídia e cultura de consumo encontram-se hoje, mais que nunca ligadas de maneira intrínseca, sobretudo, porque os produtos culturais sejam eles originalmente midiáticos ou não, invadem todas as esferas do consumismo e da produção discursiva. Assim um livro transformado em best seller pela indústria, ascende à posição de filme e seus personagens e protagonistas, passam a fazer parte do dia das pessoas através dos jogos, dos bonecos, das roupas e calçados, dos perfumes, dos acessórios etc. Além disso, os artistas que participam de sucessos de público, possuem páginas nas mídias sociais e dialogam diretamente com milhares de fãs em todo o mundo, que podem segui-los diretamente em suas páginas no Twitter, por exemplo. Esse processo é relevante para nivelar as identidades pessoais e sociais, sendo um fator de dificuldade para o reconhecimento das diversidades culturais existentes no mundo. No nosso objeto de estudo ao qual finalmente estamos chegando, ou seja, o Jornalismo e a visibilidade cultural em suas páginas, o processo não se passa de modo tão divergente. Em geral se mostra o que faz parte da cultura erudita, ou o que possui apelo midiático e de consumo e poderá render boa audiência e vender bem. E como bem afirma Mattelart ( 2005, p.146) "[...] os grandes grupos de Comunicação não estão muito dispostos a ver publicamente tratada a questão da diversidade no espaço midiático. Abordá-la implica debater o tema da censura econômica no contexto de concentração e da origem do capital financeiro em seu campo de atividades".

Assim, se de um lado, existe uma lógica de consumo relacionada aos processos de produção que "direciona" o consumo através da construção de discursos socialmente e culturalmente

Intercom - RBCC

São Paulo, v.35, n.2, p. I0I-128, jul./dez. 2012

107 
convincentes, por outro, há outra porta que se estrutura nos modos de consumo, que de uma forma ou de outra, tende a ser complementar à primeira. Clarificando, trata-se dos modos de consumo que se embasam nas formas de relacionamento e estratificação social e aí entram, não só as questões do gosto e busca de uma distinção social, mas também questões de valor simbólico que alcançam determinados bens de consumo, originalmente, não culturais por sua natureza, como uma comida, uma bebida, uma roupa ou um carro. Como ainda, as questões relacionadas ao valor de troca, quanto mais caro um determinado objeto, maior o seu valor simbólico acumulado. Deste modo, adquirir um determinado bem, como uma caneta de luxo, pode conferir prestígio a quem a possui (RÊGO, 2010, p.212).

Para Featherstone (1991, p.44) a cultura do consumo processada por meio do fluxo constante de mercadorias possui a capacidade de quebrar as barreiras sociais através da acessibilidade aos bens, sobretudo, os culturais e simbólicos, no entanto, também é capaz de acentuar o gap social pelo controle e canalização do intercâmbio de bens. Nesse sentido é que se observa que em algumas sociedades os sistemas de manutenção do status quo se protegem a partir do momento em que limitam o acesso aos bens que os classificam. Ao passo que, em outras sociedades, existe uma oferta flutuante de mercadoria que dá a impressão de que os bens simbólicos são de fácil acesso. Entende-se, pois, que o consumo realizado pelas classes sociais que possuem acumulação de capital econômico é em parte um consumo físico, mas é também um consumo simbólico, já que este está intimamente relacionado com o processo de reconhecimento e identificação social. Neste sentido é que as classes sociais se distinguem pelo consumo de três tipos de bens: a) bens de produção primária, como alimentos; b) bens e serviços relacionados a área tecnológica; e c) os bens de informação ou produção terciária, como por exemplo, os produtos midiáticos, educacionais, artes e atividades culturais e entretenimento (DOUGLAS; ISHERWOOD apud FEATHERSTONE, 1991, p.45).

Em outra frente, os que pertencem às classes sociais com menor poder aquisitivo dificilmente alcançam os três tipos de consumo. Logo, para que se possa pertencer a uma determinada 
JORNALISMO, GÊNEROS E DIVERSIDADE CULTURAL NAS REVISTAS BRASILEIRAS

classe pautada por um consumo ilimitado deve-se possuir, não só um nível econômico condizente, mas também um capital cultural suficiente, para julgar ou classificar os bens de informação e, sobretudo, não somente consumir, mas saber como e onde se deve consumir.

Em síntese, a expressão cultura de consumo, resume em si, uma compreensão, que para além de unilateral e economicista, traz uma visão holística do mundo contemporâneo, passível e aberta a intervenções de outras áreas, mas imprescindível para que se possa compreender a sociedade atual. E como nos afirma Featherstone, este tipo de cultura encontra-se focado em dois pontos, o primeiro na dimensão cultural da economia, na simbologia dos bens culturais e na capacidade que estes possuem em comunicar algo, e, o segundo, na própria economia dos bens culturais, a partir das leis da oferta, da demanda, e do comércio destes (FEATHERSTONE, 199, p.144).

\section{Jornalismo Cultural}

Não o há nada de nostalgia ou negativismo em observar que o Jornalismo Cultural brasileiro já não é como antes [...] mais que uma perda de espaço, trata-se de uma perda de consistência e ousadia e, como causa e efeito, perda de influência (PIZA, 2003, p.7).

Para Bourdieu o campo jornalístico formou-se durante o século 19 tendo como base a polaridade e concorrência entre os impressos informativos e os jornais opinativos, e, seria, portanto, o lugar de uma oposição ou cisma entre "duas lógicas e dois princípios de legitimação: o reconhecimento pelos pares, concedido aos que reconhecem mais completamente os "valores" ou os princípios internos, e o reconhecimento pela maioria, materializado no número leitores...."(BOURDIEU, 1997, p. 104).

Por outro lado, para este mesmo autor (BOURDIEU, 2005, p.99) o campo cultural formou-se a partir da evolução da vida intelectual e artística, analisadas por ele no ambiente europeu. Esse processo evolutivo teve início com as transformações sofridas pelo sistema de produção de bens simbólicos, que teriam ocorrido paralelamente à constituição do campo intelectual e artístico, que

Intercom - RBCC

São Paulo, v.35, n.2, p. I0I-128, jul./dez. 2012

109 
no seu, entender, provocou a " $[\ldots]$ autonomização progressiva do sistema de relações de produção, circulação e consumo de bens simbólicos [...]". Em sua concepção, este campo formou-se em oposição aos campos já constituídos econômico, político e religioso. Nessa conjuntura, relaciona alguns dos marcos constitutivos do campo cultural. O primeiro deles teria acontecido em Florença no século 15, "[...] com a afirmação de uma legitimidade propriamente artística [...]" (BOURDIEU, 2005, p.101) que proporcionou aos artistas legislarem o seu próprio campo. Outro fator importante na conformação do campo foi o desenvolvimento do Jornalismo, área que atraía intelectuais marginais que não se enquadravam nas demais profissões então constituídas, possibilitando a estes, um meio de sobrevivência, e, por outro lado, de independência artística.

Deste modo, e como pudemos observar nas constatações de Bourdieu expressas acima, os campos cultural e jornalístico estiveram desde sempre interligados entre si. Segundo Piza (2003, p.8) "[...] o Jornalismo Cultural, dedicado à avaliação de ideias, valores e artes, é produto de uma era que se inicia depois do Renascimento [...]".

No Brasil o advento dos primeiros periódicos impressos, em 1808, contribuiu, sobremaneira, para a formação de uma massa crítica e intelectual, que visualizou nas folhas jornalísticas, nova possibilidade de difusão da produção literária. Surgiram as folhas literárias e jornais de cunho político abriram espaço para as letras. Os folhetins eram publicados em capítulos sequenciais. A poesia e os romances ganharam destaque nos jornais. $\mathrm{O}$ relacionamento entre os escritores e o Jornalismo se intensificou, haja vista, que em grande parte, os escritores eram profissionais atuantes nos impressos (RÊGO, 2008 (A), p. 2).

Como decorrência, quando da passagem entre os séculos 19 e 20 esta vertente jornalística ganhou maior projeção e adesão, pois já existia identificação intrínseca entre literatura e imprensa no Brasil. Na opinião de Werneck Sodré (1999, p. 292), “[...] homens de letras buscavam encontrar no jornal o que não encontravam no livro: notoriedade em primeiro lugar; um pouco de dinheiro se possível". Grandes nomes da literatura nacional ganharam projeção e se mantiveram, financeiramente, através de colaborações regulares aos jornais. A opinião preponderante e vigente entre os 
intelectuais dos anos de transição entre os referidos séculos era de que o Jornalismo atuava como fator de fomento à produção e difusão da arte escrita. No entanto, a nova realidade representava, para alguns, empecilho à produção, pois a necessidade de ganhar a vida através de escritos regulares, fossem romances, folhetins, poemas ou poesias, não os permitia dedicar maior tempo à abstração e contemplação e, consequentemente, impedia produção mais qualitativa.

$\mathrm{Na}$ atualidade o Jornalismo Cultural enfrenta dilemas de diversas naturezas. Neste trabalho vamos nos reportar ao dilema que consideramos como mais importante que, do nosso ponto de vista, se refere ao processo "natural" ao Jornalismo como campo, ou seja, a necessária adequação deste aos padrões mercadológicos vigentes. Para muitos como Vargas (2004) e Azancot (2010) é quase impossível visualizar ou analisar a produção jornalística que tem como objeto a cultura e suas manifestações artísticas fora do processo imposto pelo mercado para a necessária sustentabilidade econômica dos meios de Comunicação, já que essa posição impõe pautas e modos de produção relacionados à área do entretenimento que, por sua vez, encontra-se ligada ao processo cultural. Para Piza (2003, p.51) uma das grandes perdas do Jornalismo denominado cultural é o fato de que o mesmo se produz, quase sempre, a partir do cronograma dos eventos. Por outro lado, este autor no mesmo processo analítico também enfatiza que a constante e crescente inserção de novas pautas no universo do Jornalismo Cultural, como moda e gastronomia, têm ocupado o espaço anteriormente dedicado a análise crítica de obras literárias, filmes, shows e outros produtos, entretanto, ao realizar esta ponderação, explica que essas novas abordagens consistem em [...] um ganho para o Jornalismo Cultural, pois abre suas fronteiras (PIZA, 2003, p.57). Para ele, o Jornalismo Cultural além da função primeira de anunciar e comentar as obras artísticas tem também a obrigação de "[...] refletir (sobre) os comportamentos, os novos hábitos sociais, os contatos com a realidade político-econômica da qual a cultura é parte [...] (PIZA, 2003, p. 57). Por outro lado, acrescenta que tanto a agregação de novos temas, como, a segmentação excessiva levam o Jornalismo Cultural a uma certa submissão diante do marketing. 
Faro (2006) por outro lado, reconhece a importância do Jornalismo Cultural no cenário mercadológico brasileiro, no entanto, apesar de demonstrar sua ciência acerca do relacionamento e às vezes, submissão deste tipo de Jornalismo aos processos do marketing e do mercado, possui opinião divergente da encontrada em Vargas (2004) e Azancot (2010) pois para ele é preciso [...] relativizar a assertiva que concebe o Jornalismo Cultural como uma prática estruturada exclusivamente por variáveis externas à matéria-prima com a qual trabalha sob pena de, não o fazendo, persistir um paradoxo bastante comum nos estudos e nas pesquisas sobre o Jornalismo, isto é, o divórcio com que as práticas profissionais são vistas sob o prisma teórico-conceitual e aquilo que é observado no plano empírico ou, em outras palavras, uma reflexão teórica insuficiente para dar conta da complexidade do fenômeno observado (FARO, 2006, p.4-5).

Do nosso ponto de vista, tanto Vargas, como Azancot, como Piza possuem razão quando afirmam que essa submissão, seja ela rigorosa ou leve, do Jornalismo Cultural ao mercado prejudica, empobrece e distancia o Jornalismo Cultural praticado hoje, de suas origens, por outro lado, não podemos deixar de reconhecer que a abordagem de Faro também apresenta coerência já que o campo cultural não se encontra submetido como um todo, ao campo econômico. Por outro lado, temos que reconhecer também que o relacionamento entre os dois campos aqui mencionados por último, é bem mais complexo, podendo, inclusive, acontecer o contrário, ou seja, que o mercado tenha que se submeter às lógicas da cultura, o que acontece com frequência quando tratamos dos aspectos antropológicos e étnicos, a ponto de existir uma vertente do marketing direcionado a estudar as peculiaridades culturais de cada povo, a fim de adaptar os produtos a cada mercado.

Assim é que, para nós, as intervenções do marketing no universo do Jornalismo podem ser nocivas, se o veículo adotar uma postura que trate de colocar o conteúdo jornalístico no mesmo patamar de produtos tangíveis. Nem a arte, nem o Jornalismo podem ser tratados como produtos normais, pois como afirma Bourdieu (2008, p.9), "[...] os bens culturais possuem, também, uma economia, cuja lógica específica tem de ser bem identificada 
para escapar do economicismo". Para nós, portanto, estes carregam em si, variáveis que não se encontram presentes em outros produtos. E, são estas variáveis, na verdade, atributos intangíveis e intrínsecos à sua própria natureza, que tanto atraem o público.

Por outro prisma, as sugestões do marketing podem ser bem-vindas ao Jornalismo; a segmentação pode, por exemplo, permitir que os textos de interesse de determinado público, tratados de forma frívola muitas vezes, possam ser trabalhados profundamente em uma publicação especializada.

Nas próximas páginas trataremos de analisar o Jornalismo e a visibilidade cultural nas páginas das revistas já mencionadas no início deste texto.

\section{Visibilidade Cultural nas publicações brasileiras}

No Brasil e, como bem afirma Faro (2006), há um crescente número de publicações especializadas em diversas áreas, grande parte delas aborda aspectos culturais, outras tantas se voltam para a história, a literatura, a psicanálise. Essa crescente evolução do número de revistas no mercado editorial de certo modo contraria a versão mais comum de que esse segmento mercadológico esteja em declínio. No entanto, nem sempre um maior número de veículos de Comunicação significa uma maior democratização da informação e do acesso à mesma por parte da população.

$\mathrm{Na}$ presente investigação, nos interessa identificar, primeiramente, a visibilidade das manifestações culturais e o grau de acessibilidade destas atividades às revistas em análise, a saber: Bravo, Cult e Brasileiros.Depois, entramos no processo jornalístico e pretendemos analisar os gêneros jornalísticos mais utilizados por estas publicações, já que conforme a tradição do Jornalismo Cultural, há ou deveria haver, uma preponderância da opinião.

A análise será, portanto, realizada em duas vertentes, na primeira realizaremos um diagnóstico quantitativo de quais manifestações possuem visibilidade contumaz nos periódicos aqui tratados, e ainda sua origem geográfica. A segunda terá como base a análise de conteúdo dos textos das revistas, a partir da estratégia do emparelhamento que $[. .$.$] consiste em associar os dados recolhidos a$

Intercom - RBCC 
um modelo teórico com a finalidade de compará-los" (LAVILLE $\&$ DIONE, 1999, p.227). Neste momento, estaremos comparando o Jornalismo das revistas aos conceitos dos gêneros jornalísticos opinativo, informativo, interpretativo, diversional e de serviços, segundo Marques de Melo (2003, 2006a e 2006b).

Por último, esclarecemos que na fase inicial estaremos adotando como para parâmetro a UI- Unidade de Informação de Morin (1974) que define cada matéria jornalística como um todo informativo, independente do espaço ocupado pela mesma na mancha gráfica, ou seja, tanto pode ser uma notícia, uma nota ou uma grande reportagem, a contagem é realizada como uma unidade de informação.

A amostra analítica compõe-se dos exemplares da Revista Bravo $^{1}$ 152, 153, 154 e 155 referentes aos meses de abril, maio, junho e julho de 2010, como também dos exemplares da Revista Cult ${ }^{2}$ 145, 146, 147 e 148 também referentes ao mesmo período e, por último, os exemplares de número 33, 34, 35 e 36 da Revista Brasileiros ${ }^{3}$.

\section{O Visível e o Invisível}

Antes de iniciarmos a análise propriamente dita, é válido destacar a qualidade estética e editorial das três publicações. É

\footnotetext{
${ }^{1}$ A Revista BRAVO é uma publicação da Editora Abril, um dos maiores grupos editoriais brasileiros, que possui em seu portfólio dezenas de periódicos. BRAVO encontra-se em seu $14^{\circ}$ ano e nasceu como uma publicação segmentada e direcionada ao público que tem interesse em conteúdo cultural. Além da revista mensal há o site BRAVO ONLINE que não só reproduz as editorias do periódico como abre novos debates. Maiores informações: http://bravonline.abril.com.br/index.shtml . ${ }^{2}$ A CULT encontra-se no mercado há 15 anos e é uma publicação da Editora Bregantini, mas a sua principal característica de sustentabilidade para além dos anúncios localizados em suas páginas é que a mesma, desde sua criação, conta com o patrocínio dos recursos incentivados pelo Governo Federal através da Lei Rouanet. É uma revista que volta-se para a visibilidade cultural e para o debate filosófico. Maiores informações: http://revistacult.uol.com.br/home/ .

${ }^{3}$ Das três publicações analisadas a Brasileiros é a mais nova. Com apenas seis anos, Brasileiros se dedica ao tema da cultura, mas também possui editorias para política, esportes e outras temas que se coloquem pontualmente como interessantes e importantes. Maiores informações: http://www.revistabrasileiros.com.br/ .
} 
visível o trato esmerado que todas possuem com a informação e com a opinião acerca dos assuntos relacionados ao universo cultural. No entanto, é também válido ressaltar que todas são publicações da região sudeste, aonde o mercado editorial é mais desenvolvido no Brasil, como também o mercado cultural, o que faz com que a maioria das pautas sejam, com maior ou menor intensidade, oriundas dos estados lá localizados, com prioridade para Rio de Janeiro e São Paulo e suas respectivas capitais. Isto reflete a realidade, mas não justifica a visibilidade restrita que o restante da nação possui nas revistas aqui mencionadas.

É bem verdade que as três atendem aos princípios que regem o Jornalismo, ou seja, atualidade, periodicidade, difusão coletiva e universalidade, e, portanto, se pautam pelos critérios de noticiabilidade definidos pelo Jornalismo, e que definem o que, quando e onde, pode vir a se tornar pauta jornalística e/ou notícia. Dentre esses critérios e valores notícia, muitos como a importância e relevância do acontecimento medidas pelo número de pessoas envolvidas, ou o interesse para o maior número de pessoas pela capacidade de "sedução" e entretenimento, ou questões como qualidade estética, atualidade etc., podem colocar como prioritária uma notícia da OSESP-Orquestra Sinfônica do Estado de São Paulo, em detrimento de um evento que envolva a Orquestra Sanfônica do Piauí, ou o Coral dos Vaqueiros do pequeno município de União também no Piauí, que normalmente só ascendem à mídia nacional de referência pelo critério do exótico ou da curiosidade.

O peso, portanto, que as três publicações que possuem circulação nacional dão aos produtos culturais de suas regiões é bem diverso do que possuem as manifestações culturais de outras regiões em suas páginas.

Por outro lado, as manifestações que se visibilizam também estão entre as mais consagradas, raras são as novas iniciativas culturais que ganham as páginas das revistas como veremos adiante.

${ }_{4}^{4}$ Orquestra de Sanfoneiros

Intercom - RBCC 


\section{Quem aparece}

Em Cult as manifestações culturais que possuem maior visibilidade, nos exemplares analisados, são a literatura, a música e o teatro, no entanto, cabe ressaltar aqui que é uma publicação que divide, ou, como dizem os espanhóis, que comparte o seu espaço entre cultura, filosofia, ciência, política e outras temas. Assim, a cada exemplar além do dossiê normalmente voltado para temas filosóficos encontramos uma grande entrevista realizada com personagens destacados em suas áreas de atuação como podemos conferir em: Por uma ética mundial da esperança, entrevista realizada com o padre Carlos Josaphat sobre o seu livro Ética Mundial, no exemplar de número 147, ou ainda, a entrevista com a geneticista Lygia da Veiga Pereira que discute as questões éticas das últimas descobertas da ciência, no número 148 de Cult.

Nos dossiês são tratados temas sobre o prisma filosófico como: Ética em temos de crise na edição de número 145, ou $O$ Amor e as (des) razões do coração no número 146, e ainda temas políticos como A Era Lula no 148, no qual as conquistas e evoluções do Brasil são apresentadas. Contudo, em se tratando de visibilidade das manifestações culturais o gráfico 1 nos fala sobre como estas se encontram nas páginas da revista.

Gráfico 1: Visibilidade manifestações em CULT

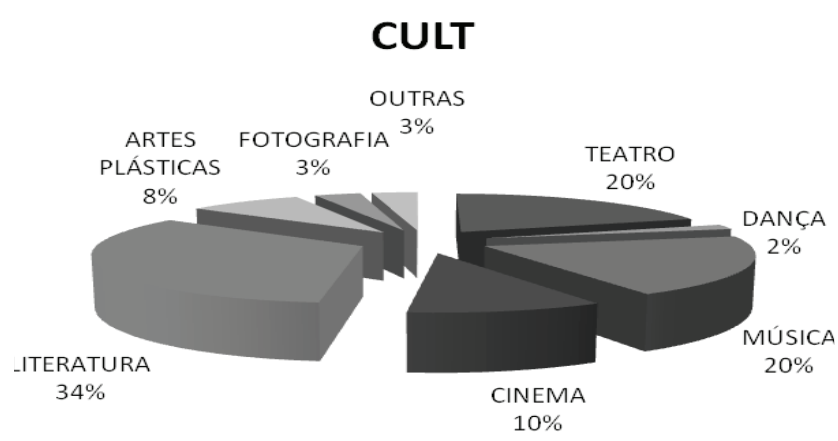

Fonte dos dados: CULT

116

Intercom - RBCC

São Paulo, v.35, n.2, p. $101-128$, jul./dez. 2012 
Na Revista Bravo o gráfico da visibilidade coloca em primeiro lugar as matérias de opinião e informação sobre músicam e cinema, seguidos pelo teatro, artes plásticas e literatura. A bem da verdade, essas são as editorias da revista, com a ressalva de que o teatro divide a mesma editoria com dança, mas nos exemplares analisados o espaço foi ocupado quase que totalmente pelo teatro. Além disso, Bravo também possui as demais seções na qual encontramos a Carta do Editor da revista, a seção de cartas do leitor, uma outra seção denominada Primeira Fila, outra que fala do site e uma que é destinada a um texto de Ficção Inédita.

Bravo apresenta qualidade jornalística e estética mas pouco ousa em termos de temas novos, prefere no entanto, ousar dentro do conhecido como na reportagem $O$ Crime que marcou Polanski no exemplar 154 no qual expõe detalhes da vida do escritor, ou a matéria sobre Lady Gaga e seu relacionamento com o YouTube no número 153. O gráfico a seguir nos dá indícios de quem aparece na Bravo.

Gráfico 2: Visibilidade manifestações em BRAVO

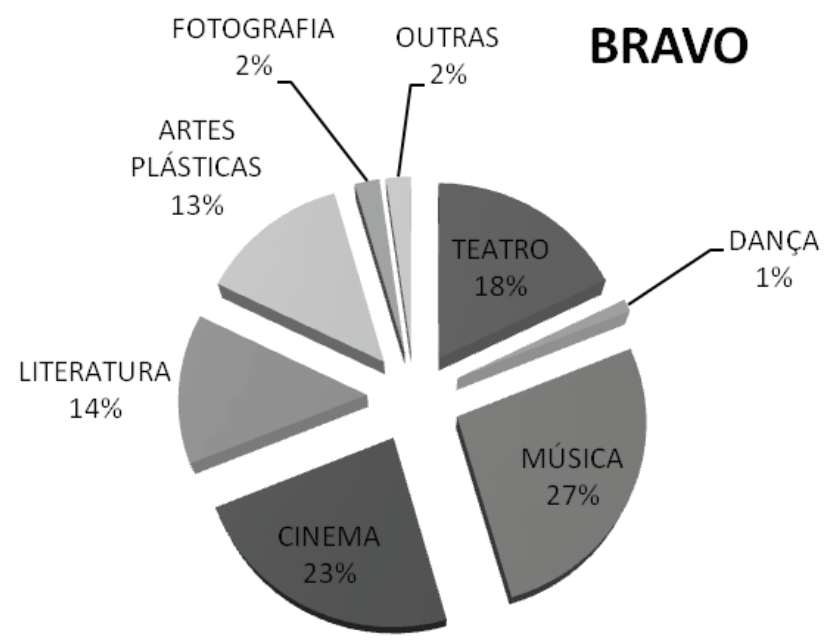

Fonte das informações: BRAVO 
A Revista Brasileiros possui seções diversas, a intitulada 30 dias, por exemplo, se divide por temas abordados que podem inclusive se repetir assim, encontramos: Cultura/Arte, Cultura/ Cinema, Cultura/Poesia, Cultura/Música, Cultura/Livro, Pequenos contos, que se duplicam em cada edição. Além disso, há um especial sobre determinado tema e ainda outros temas relevantes da política, do esporte etc.

Durante o período de investigação vale destacar as reportagens especiais da edição de número 33, de abril de 2010, que não apenas falou sobre 50 anos de Brasília, mas tratou da cidade e seus habitantes atualmente. E ainda as matérias que compuseram o Especial Novo Nordeste na edição de número 35 de junho deste ano, que procurou mostrar os avanços econômicos e sociais da região na atualidade. Dentre as três revistas, esta talvez seja a que mais arrisca sair um pouco das artes consagradas e enveredar por outros caminhos. É que o faz na matéria O Auto da Academia de Cordel da edição de número 35.

Gráfico 3:Visibilidade manifestações em BRASILEIROS

\section{BRASILEIROS}

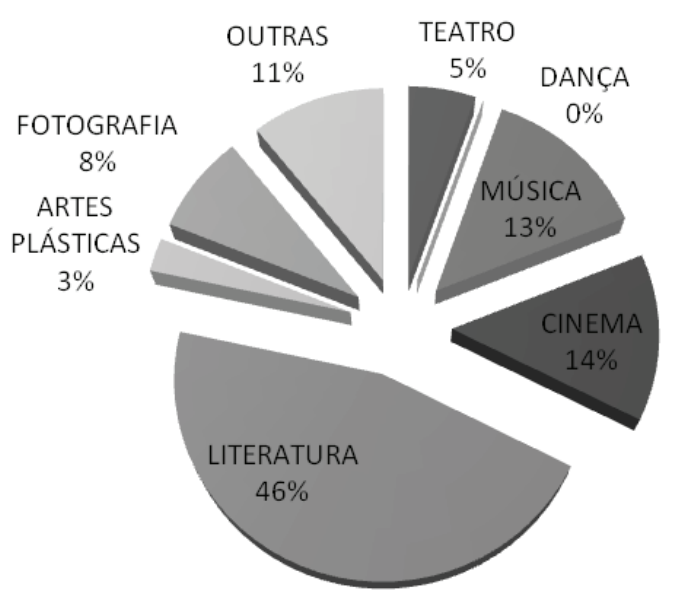

Fonte das informações: BRASILEIROS 
Mais um destaque a fazer, é que nas três revistas aqui analisadas o segmento relativo a literatura encontra-se bem à frente dos demais, sobretudo, em Brasileiros e em Cult, mas também em Bravo que além das resenhas e críticas possui seções indicativas de novas publicações e lançamentos de todas as áreas.

\section{Lócus de quem aparece}

Na Revista Cult cerca de 70\% das matérias relativas à cultura são concernentes a temas nacionais e o restante se refere à manifestações de origem externa, incluindo os livros de autores internacionais. Neste universo mundial, $60 \%$ se referem a produtos/ personagens ou contextos culturais europeus, $27 \%$ referentes aos oriundos da América do Norte, $6 \%$ da Ásia e os demais possuem visibilidade nula ou próximo disso. Essa posição européia destacada é concernente à visibilidade da literatura em suas páginas.

Por outro lado, quanto à visibilidade nacional, Cult volta e meia destaca algum evento de outras regiões como o SALIPI- Salão do Livro do Piauí e o Ceará Literário, mas o grosso de suas páginas se destina ao que se produz no sudeste.

Gráfico 4: Locus de quem aparece na CULT

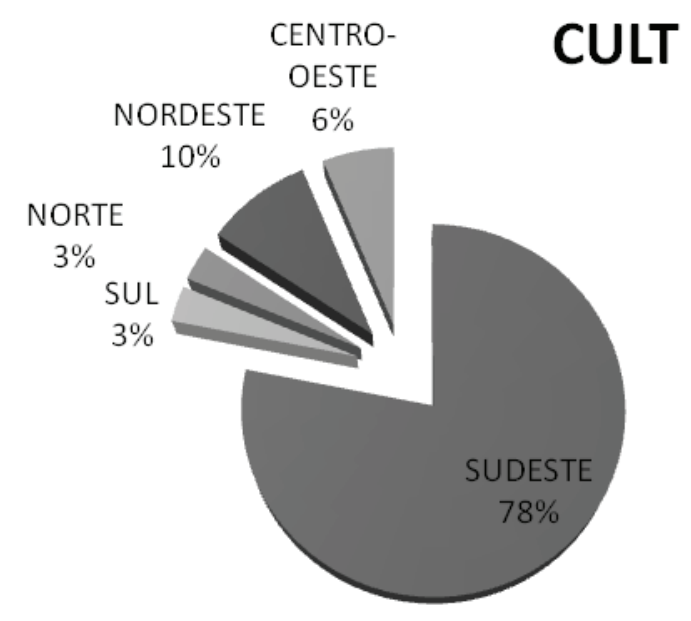

Fonte das informações: CULT

Intercom - RBCC

São Paulo, v.35, n.2, p. I0I-I28, jul./dez. 2012 
Bravo, por sua vez, realiza cobertura mais abrangente que Cult, pois possui setores que cobrem os lançamentos comerciais em cada uma de suas editorias destacando os livros, discos e demais produtos de várias partes do planeta. Assim, considerando os textos opinativos e o material informativo, incluindo um grande número de pequenas notas e notícias, verificamos que nos exemplares analisados, cerca de $60 \%$ das matérias se referem a temas de origem internacional enquanto que $40 \%$ são de produtos ou temais culturais brasileiros.

No ambiente internacional de Bravo destacam-se produtos, personagens e contextos culturais da Europa com 56\% e da América do Norte com 30\%, os demais possuem participam irrelevante.

No Brasil, Bravo dá maior destaque ao que acontece na pauta cultural da região sudeste, mas volta e meia destaca alguma coisa que acontece no sul, embora a paridade seja bem desigual, como podemos conferir a seguir, mas também é possível encontrar notícias sobre o Festival Amazonas de Ópera, o Festival da Banana de Goiânia ou Conexão Vivo Belém Música.

Gráfico 5: Locus de quem aparece na BRAVO

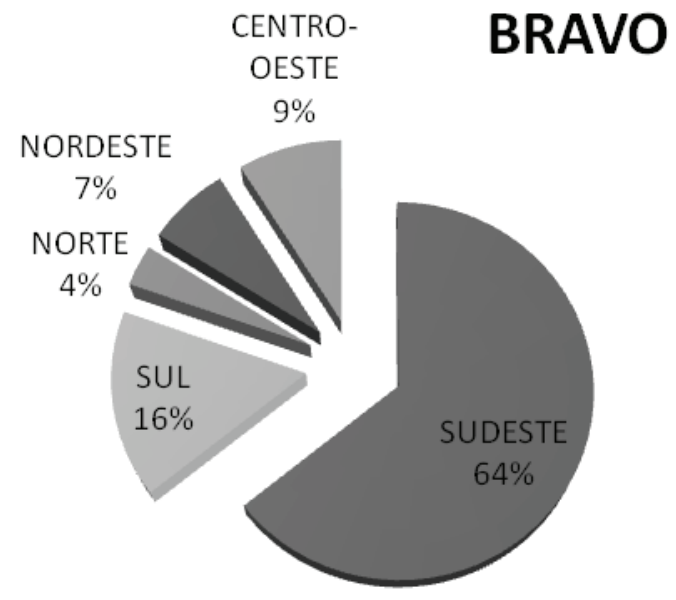

Fonte das informações: BRAVO 
Nas edições da Revista Brasileiros analisadas cerca de $80 \%$ das matérias sobre cultura se referem a temas nacionais e apenas $20 \%$ são de assuntos relativos ao ambiente externo. Deste modo, os temas internacionais que aparecem com maior incidência são os referentes a produtos/personagens ou contextos culturais da América do Norte e da Europa.

No Brasil, Brasileiros dá destaque ao que se produz e a própria agenda do sudeste, no entanto, abre espaço as rendeiras de Parnaíba-Piauí na edição de número 34, por exemplo, no entanto, as regiões sul e norte não estão visíveis na publicação nos exemplares analisados.

Gráfico 6: Locus de quem aparece na BRASILEIROS

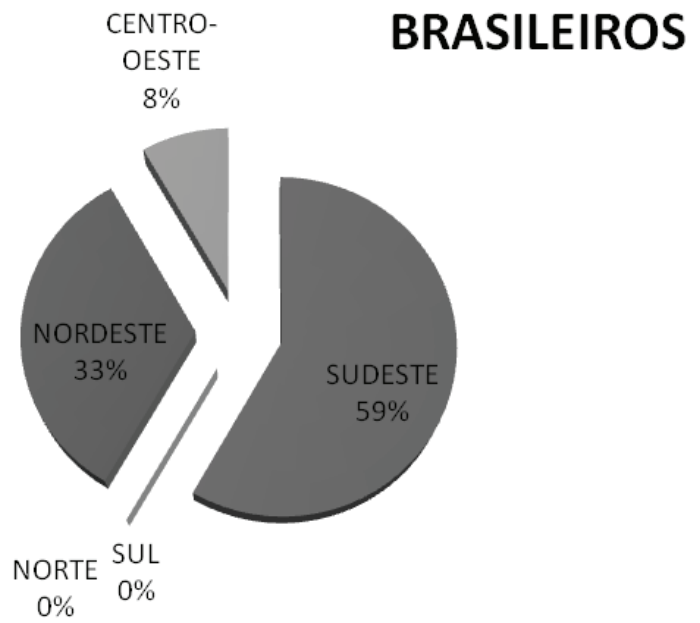

Fonte das informações: BRASILEIROS

\section{Como quem aparece, aparece - os Gêneros Jornalísticos mais contumazes}

Neste ponto, analisaremos os textos das revistas sobre o prisma da análise de conteúdo por emparelhamento tendo como base as conceituações teóricas sobre gêneros jornalísticos de Marques de Melo (2003; 2006a; 2006b. Neste sentido é que Marques de 
Melo (2003, p.65) em estudo da década de 1980, fala somente em dois gêneros e/ou categorias: o informativo e o opinativo. $\mathrm{O}$ primeiro com os formatos: nota, notícia, reportagem e entrevista. O segundo se dividiria em editorial, comentário, artigo, resenha, coluna, crônica e caricatura e carta. Este autor ${ }^{5}$ fez revisão recente desta classificação, passando a incorporar os gêneros interpretativo, utilitário(ou de serviços) e diversional. O primeiro, o autor havia excluído da proposta anterior por não ter verificado em sua pesquisa de livre-docência a existência do mesmo na imprensa brasileira da época. Atualmente, porém, Marques de Melo adota para o interpretativo os formatos: dossiê, perfil, enquete e cronologia. Para o utilitário (ou de serviços) os formatos: indicador, cotação, roteiro e serviço, já o diversional divide em história de interesse humano e história colorida.

A revista Cult, intitulada Revista Brasileira de Cultura é uma publicação mensal e patrocinada, à época das edições aqui analisadas, com recursos públicos através da lei Rouanet, como dito anteriormente. Esta revista a princípio aparentava ser apenas uma publicação segmentada e especializada em conteúdo cultural, filosófico e científico, mostrou-se, no entanto, como um veículo jornalístico com $70 \%$ das UI ocupadas com textos e gêneros jornalísticos.

$\mathrm{Na}$ Cult a predominância fica por conta dos gêneros opinativos, mas as notas tiram a diferença, para o informativo, além de haver entrevistas e reportagens. O Jornalismo de serviço aparece timidamente, mas marca presença.

Os 30\% que sobram são ocupados com textos que formam o dossiê Cult a cada mês. Normalmente são temas filosóficos, como frisamos acima. Para desenvolver estes temas a direção da revista convida especialistas ou filósofos que escrevem em formato de ensaio, fugindo do texto jornalístico. A seguir conferimos os dados referentes aos gêneros jornalísticos praticados pela Cult.

${ }^{5}$ Melo. José Marques de. Anotações de sala de aula. UMESP. 2006 
Gráfico 7: Gêneros Jornalísticos CULT

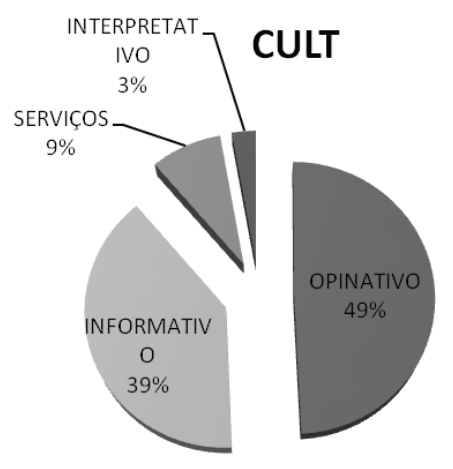

Fonte das Informações: CULT

A revista Bravo tanto divulga, como comenta, crítica e indica os eventos e manifestações culturais que acontecem no Brasil e no mundo e o faz explorando os gêneros jornalísticos.

São destaques nesta revista com editorias exclusivas: as artes plásticas, a música, o cinema, o teatro e a literatura são destaques em Bravo, como visto anteriormente.

O gênero predominante é o opinativo com grande número de resenhas e críticas, seguidas de comentários e artigos, além da seção de cartas. Depois seguem os gêneros, utilitário e informativo, o primeiro localizado através das seções de serviços e roteiros que existem em cada editoria, já o segundo através de uma boa quantidade de notas, algumas entrevistas e poucas reportagens.

Uma última observação ainda deve ser feita em relação ao Jornalismo informativo encontrado na revista. É que nem sempre segue a estrutura rígida do lead, apresentando um estilo mais livre.

Por último, Brasileiros se destaca por duas questões: a primeira é que há quase um empate técnico entre informação e opinião; a segunda é que os textos interpretativos surgem com mais força. 
Gráfico 8: Gêneros em BRAVO

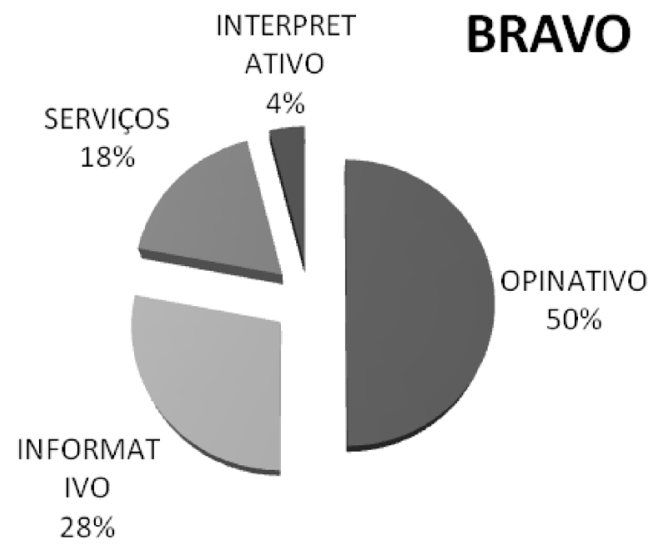

Fonte das informações: BRAVO

Gráfico 9: Gêneros em Brasileiros

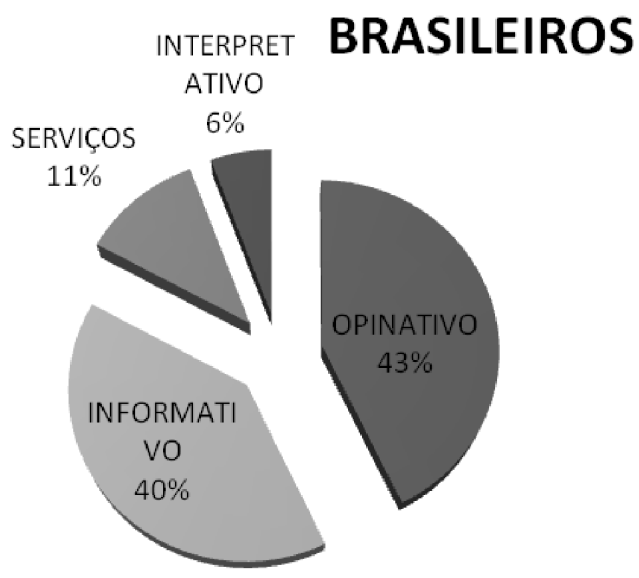

Fonte das informações: Brasileiros

Nas três revistas percebe-se a preponderância do gênero opinativo, o que comprova que o Jornalismo Cultural continua com essa característica original, muito embora haja uma tendência 
visível já verificada quando analisamos a Revista Piauí em um trabalho anterior (RÊGO, 2008b), de se praticar um Jornalismo informativo mais livre, sem a necessidade da temporalidade veloz, da estrutura objetiva do lead, das "caixinhas" do fazer jornalístico objetivo que tanto limitam a criatividade do profissional e, ao mesmo tempo, de se adotar um estilo mais livre e quase literário em alguns casos. Por outro, há também uma tendência a um uso muito maior dos recursos visuais e interativos, colocando o texto de uma mídia ( a revista) em contato com os textos de outra mídia ( o site na internet). Há ainda textos em que informação e opinião se misturam o tempo todo dificultando a classificação dos mesmos em um gênero. Quando detectamos esse estilo textual optamos por não classificar o texto nos parâmetros existentes e aqui adotados.

\section{Considerações finais}

As revistas aqui analisadas são publicações e, portanto, produtos culturais produzidos e consumidos no ambiente da cultura de consumo e da cultura da mídia. São também produtos que se referem a outros produtos, que dão destaque a determinadas formas de manifestação cultural, enquanto silenciam outras. São referências em seus segmentos de atuação proporcionando distinção cultural e social tanto aos envolvidos nas atividades culturais divulgadas, como ao público seleto que consome tanto os produtos culturais, como a própria revista.

$\mathrm{O}$ fato de possuírem reputação de meios de referência nacional transforma o discurso jornalístico simples que veiculam, em discurso formador do gosto e influente no processo que diferencia as pessoas que as lêem. E mais, influem ainda no consumo dos bens e produtos culturais, avalizando com seu julgamento crítico alguns e condenando outros.

É bem verdade que seu alcance é limitado ao número de leitores que possuem, e que este alcance é bem menor do que o das demais mídias de massa, como a televisão, por exemplo; no entanto, vale recordar que são publicações segmentadas e direcionadas a um grupo que se auto-identifica pelo conteúdo veiculado e pelos interesses em comum. Nessa esfera mercadológica os iguais 
se tornam mais e mais iguais, e os que desejam alcançar o status quo social e/ou cultural dos que já se encontram nesse patamar, devem consumir as mesmas fontes de informação, os mesmos produtos e bens culturais visando sanar o gap que julgam possuir.

É destacável a qualidade jornalística e estética dos veículos analisados, assim como, a sua preocupação em "cobrir" o ambiente nacional, no entanto, é visível a disparidade com que esta cobertura é realizada. Nos três casos, por mais que se visualize diversas formas de manifestações artísticas em suas páginas, nenhuma delas consegue chegar perto de abranger o que há em termos de diversidade cultural nacional que reúne milhares de produções, todas aptas e disponíveis para obter visibilidade.

A dificuldade de visibilidade prejudica a fruição e vice-versa. O mercado cultural de outros centros nacionais que não possuem um mercado midiático consolidado também se ressente. Tudo se encontra interligado e os veículos de Comunicação possuem sua parcela de contribuição, para o bem ou para o mal. Não queremos com isso imputar qualquer tipo de culpa ou manifestar juízo de valor referente à atuação das revistas aqui estudadas, no ambiente cultural nacional, no entanto, cremos que seja necessário que os meios de Comunicação de todo o Brasil se engajem com maior força no processo de divulgação das manifestações culturais, tanto visando a democratização e o acesso popular às mesmas, quanto objetivando colocar o maior número possível de eventos/personagens ou produtos culturais na página que congrega a identidade brasileira.

Quanto ao Jornalismo praticado pelas revistas analisadas, como destacamos antes, este se mostrou preponderantemente opinativo, como dito, mas apresenta novidades na mescla da informação e da opinião, assim como, um maior uso dos recursos visuais e interativos. Por outro lado, Bravo se detém também na questão da agenda cultural e utiliza o gênero Jornalismo de serviços, este entendido conforme Marques de Melo (2006b).

\section{Referências}

AZANCOT, Nuria. Redatora do El Mundo vê o jornalismo cultural refém do mercado. COMUNIQUE-SE. Disponível em: < http://www.comunique-se. 
com.br/index.asp?p=Conteudo/NewsShow.asp\&p2 =idnot\%3D55703\%26Edito ria\%3D8\%26Op2\%3D1\%26Op3\%3D0\%26pid\%3D1388605696\%26fnt\%3Dfnt $\mathrm{nl}>$. Acesso em: 05 maio 2010.

BOURDIEU, Pierre. A Distinção - crítica social do julgamento. Porto Alegre: Zouk, 2008.

. A economia das trocas simbólicas. São Paulo: Perspectiva, 2005.

. Sobre a televisão. Rio de Janeiro: Jorge Zahar, 1997.

FARO, J.S. Nem tudo que reluz é ouro- contribuição para uma reflexão teórica sobre o Jornalismo Cultural. In: III Encontro Nacional de Pesquisadores em Jornalismo -SBPJOR. Porto Alegre, 27 a 29 de nov. 2006. Anais...

FEATHERSTONE, Mike. Cultura de consumo y posmodernismo. Buenos Aires: Amorrortu Editores, 1991.

KELLNER, Douglas. A cultura da mídia. São Paulo: EDUSC, 2001.

LAVILLE, Christian \& DIONNE, Jean. A Construção do Saber-Manual de metodologia da pesquisa em ciências humanas. Belo Horizonte: Editora UFMG. Porto Alegre: Editora ARTMED, 1999.

MATTERLART, Armand. Diversidade cultural e mundialização. São Paulo: Parábola, 2005.

MARQUES DE MELO, José. Jornalismo Opinativo: gêneros opinativos no Jornalismo brasileiro, 3a ed., Campos do Jordão: Ed. Mantiqueira, 2003.

. Teoria do jornalismo. São Paulo: Summus, 2006a.

. Anotações de sala de aula. 2006b.

MORIN, Violet. Tratamiento periodistico de la información. A.T.E. Barcelona: Colección Libros de Comunicación Social, 1974.

PIZA, Daniel. Jornalismo cultural. São Paulo: Contexto, 2003.

RÊGO, Ana Regina. Comunicação corporativa, marketing e política cultural- Brasil e Espanha. SBC- SP: UMESP, Barcelona: UAB. CAPES, 2010.

RÊGO, Ana Regina. Imprensa piauiense- entre a literatura e a política. In: VI Congresso Nacional de História da Mídia. Niterói-RJ, 13 a 16 mai. 2008a.

Intercom - RBCC

São Paulo, v.35, n.2, p. I0I-I28, jul./dez. 2012 
Anais...

RÊGO, Ana Regina. O Jornalismo e os gêneros nos impressos brasileiros. In: III Terceiras Jornadas Internacionais de Jornalismo. Porto, 14, mai, 2008b. Anais...

SODRÉ, Nelson Werneck. História da Imprensa no Brasil. 4 ed. Rio de Janeiro: Maud, 1999.

VARGAS, Herom. Reflexões sobre o Jornalismo Cultural contemporâneo. Estudos de Jornalismo e Relações Públicas. São Bernardo do Campo, UMesp, ano 2, n. 4, p.52-70, jun/dez., 2004.

\section{Revistas}

BRASILEIROS. Ano 4. n.33, abr. 2010.

BRASILEIROS. Ano 4. n.34, mai.2010.

BRASILEIROS. Ano 4. n.35, jun. 2010.

BRASILEIROS. Ano 4, n.36, jul. 2010.

BRAVO. Ano 12, n.152, abr. 2010.

BRAVO. Ano 12, n. 153, mai. 2010.

BRAVO. Ano 12, n.154, jun.2010

BRAVO. Ano 12, n.155, jul.2010

CULT. Ano 13. n.145, abr. 2010.

CULT. Ano 13. n.146, mai.2010.

CULT. Ano 13.n.147, jun. 2010.

CULT. Ano 14, n.148, jul. 2010 